\title{
生物燃料乙醇产业未来发展的新模式
}

\author{
王梦 ${ }^{1,2}$, 田晓俊 ${ }^{2}$, 陈必强 ${ }^{1}$, 林海龙 $^{2}$, 岳国君 ${ }^{2}$ \\ （1. 北京化工大学生命科学与技术学院，北京 100029；2. 国投生物科技投资有限公司，北京 100034）
}

\begin{abstract}
摘要：燃料乙醇产业是我国重点培育和发展的战略性新兴产业之一, 在国家推进工业化与信息化深度融合的背景下, 利用我 国在工业互联网和第五代移动通信 $(5 \mathrm{G})$ 技术上的优势, 以大数据、数字孪生和区块链等新技术为支撑, 推进生物燃料乙 醇产业的智能化、安全化发展新模式, 对于我国燃料乙醇产业高质量发展具有重要意义。本文梳理并总结了国内外生物燃料 乙醇产业的发展现状, 凝练产业智能化、安全化发展面临的问题, 提出了生物燃料乙醇产业智能生产新模式、安全生产新模 式和产业管理新模式的总体思路。研究表明, 我国生物燃料乙醇产业发展应在国家、地方和企业的保障与积极配合下, 从国 家战略层面引导产业发展, 推进生物燃料乙醇产业基地特色化、联合化、智能化发展; 加大 “产学研” 合作力度, 创新生产 模式和生产技术, 提升国际市场竞争力; 进一步开展关键技术攻关, 实现以纤维素类生物质为原料的生物燃料乙醇技术突破, 为国家粮食安全问题提供战略储备。
\end{abstract}

关键词：燃料乙醇；智能生产；安全生产；新模式

中图分类号：TK6；S216.2 文献标识码：A

\section{Future Modes of Fuel Bioethanol Industry}

\author{
Wang Meng ${ }^{1,2}$, Tian Xiaojun ${ }^{2}$, Chen Biqiang ${ }^{1}$, Lin Hailong ${ }^{2}$, Yue Guojun ${ }^{2}$ \\ (1. College of Life Science and Technology, Beijing University of Chemical Technology, Beijing 100029, China; \\ 2. SDIC Biotech Investment Co., Ltd., Beijing 100034, China)
}

\begin{abstract}
The fuel bioethanol industry is one of the strategic emerging industries that China focuses on cultivating and developing. Against the background of the country's deep integration of industrialization and informatization, intelligent and safety production, which can be realized relying on China's advantages in the Industrial Internet and 5G technology and supported by new technologies such as big data, digital twins, and blockchain, can promote the high-quality development of the fuel bioethanol industry in China. This paper summarizes and analyzes the status and problems of the fuel bioethanol industry, and proposes the general idea for future modes in intelligent production, safety production, and industrial management of the fuel bioethanol industry. The development of the fuel bioethanol industry should be guided at the national strategic level and requires cooperation among the state, local governments, and enterprises, thus to promote the characteristic, joint, and intelligent development of bioethanol industrial bases. The cooperation between industry, universities, and research institutions should be strengthened to innovate production modes and technologies and to promote international competitiveness. Furthermore, key technologies should be developed to realize the production of fuel bioethanol using cellulose-based biomass as the raw material, thereby providing strategic reserves for ensuring national food security.
\end{abstract}

Keywords: fuel bioethanol; intelligent production; safety production; future modes

收稿日期 : 2019-12-17; 修回日期 : 2020-02-15

通讯作者：林海龙，国投生物科技投资有限公司高级工程师，研究方向为生物能源；E-mail: linhailong@sdic.com.cn

资助项目：中国工程院咨询项目 “新兴产业发展战略研究（2035）”(2018-ZD-12); 中国工程院咨询项目 “基于糖平台的绿色生物制造产 业发展战略研究” (2018-XZ-13)

本刊网址 : www.engineering.org.cn/ch/journal/sscae 


\section{一、前言}

按照我国《可再生能源法》的定义, 生物质能 是指利用自然界的植物、粪便及城乡有机废物转化 成的能源 [1]。生物燃料则是生物质能的载体, 泛 指由生物质组成或经加工得到的固体、液体或气体 燃料。

燃料乙醇是目前世界上应用最广泛的可再生能 源, 也是我国重点培育和发展的战略性新兴产业之 一, 符合我国能源供给侧结构性改革和能源发展 战略的方向。生物燃料乙醇是联通农业、能源和 环保的国家战略性新兴产业, 在保障国家粮食安 全、解决能源危机和环境治理等方面将发挥更大的 作用 [2]。一方面, 燃料乙醇作为传统石化能源的 替代品之一, 有助于进一步优化我国能源结构, 降 低石油对外依赖度, 保证能源安全; 另一方面, 生 物燃料乙醇是粮食生产的 “推进器” 和粮食安全的 “调节阀”，通过生物燃料乙醇的生产和加工，有助 于稳定粮食生产, 是解决 “问题粮食” 的唯一现实 途径, 可以有效促进农业健康发展。同时, 燃料乙 醇还是一种清洁能源, 是汽油最环保的增氧剂和辛 烷值促进剂, 能够有效减少温室气体和 $\mathrm{PM}_{2.5}$ 排放, 对于改善大气环境质量有着积极作用。

目前美国和巴西燃料乙醇的生产及消费在全球 居于领先地位, 主要得益于稳定且廉价的原料供应 和可再生能源的激励政策。以美国为例, 2019 年 美国共计生产了 $4.717 \times 10^{7} \mathrm{t}$ 乙醇, 替代了从 5 亿 桶原油中提炼的汽油, 创造了 320 亿美元的收入, 支持了 6.8 万个直接工作岗位和 28 万个间接工作 岗位。十多年来, 我国生物燃料乙醇产业累计生 产量超过 $1.98 \times 10^{7} \mathrm{t}$, 调合汽油近 $2 \times 10^{8} \mathrm{t}$, 改善 了现有的能源消费结构, 间接减少原油进口量达 $3.2 \times 10^{8} \mathrm{t}$; 消化人畜不能食用的玉米、水稻、小 麦等粮食作物 $1.43 \times 10^{7} \mathrm{t}$, 副产 $1.24 \times 10^{7} \mathrm{t}$ 高蛋白 饲料; 累计减排 $\mathrm{CO}_{2}$ 当量 $2.52 \times 10^{7} \mathrm{t}$, 减少汽车 尾气有害物质排放，替代甲基叔丁基醚（MTBE） 使用，保护了地下水资源。在拉动农业、保护环境、 替代能源三大战略方面初见成效, 社会、经济和 生态效益显著。

近年来，一系列国家层面的扶持和推广政策 陆续出台, 推动了我国燃料乙醇产业的发展步伐。 2016 年, 国家能源局发布《生物质能发展 “十三五”
规划》, 提出加快生物液体然料的示范和推广, 尤 其是推进燃料乙醇的应用。2017 年, 我国确定加 快发展燃料乙醇的策略, 15 个国家部委联合印 发《关于扩大生物燃料乙醇生产和推广使用车用生 物乙醇汽油的实施方案》, 大力推广燃料乙醇的使 用; 之后, 又确定了《全国生物燃料乙醇产业总 体布局方案》。2018 年我国燃料乙醇装置产能新增 近 $1 \times 10^{6} \mathrm{t}$, 总量达到 $3.7 \times 10^{6} \mathrm{t}, 2020$ 年在全国范 围推广后, 燃料乙醇年需求量将超过 $1 \times 10^{7} \mathrm{t}$, 而 燃料乙醇市场至少有 $7 \times 10^{6} \mathrm{t}$ 的缺口 [3]。我国燃料 乙醇产业即将迎来广阔的发展空间和重大的发展机 遇。尽管生物燃料乙醇产业已基本形成了从生产、 混配、储运到销售的完整产业体系, 但整体发展与 美国仍有很大差距。在国家推进工业化与信息化 深度融合的背景下, 利用我国工业互联网和第五 代移动通信 $(5 \mathrm{G})$ 技术优势, 以大数据、数字孪 生和区块链等新技术为支撑, 结合先进信息管理 系统, 探讨未来生物燃料乙醇工厂的智能化、安 全化发展新模式, 对于我国燃料乙醇产业高质量 发展具有重要价值。

\section{二、生物燃料乙醇产业发展现状}

燃料乙醇产业是国家重点推广的新型产业, 是 基于石油危机和控制大气污染所产生的新兴绿色产 业之一，目前我国生物燃料乙醇主要生产方式分为 粮食乙醇和纤维素乙醇。使用生物发酵法制乙醇在 我国主要经历了 3 个发展阶段: 1 代燃料乙醇以玉 米、小麦等陈粮为原料, 通过生物发酵将淀粉转化 为乙醇； 1.5 代燃料乙醇以非粮农作物（木薯）为原 料, 同样通过发酵将淀粉转化为乙醇, 虽然此路线 可避免与人争粮的问题, 但目前该原料主要依赖于 进口; 2 代燃料乙醇主要是纤维素乙醇, 优势在于 原料充足, 但由于我国的纤维素乙醇关键技术还没 有实现突破, 所以成本与粮食乙醇相比偏高。整体 来看, 我国燃料乙醇生产水平处于从 1 代向 1.5 代 过渡的阶段, 2 代纤维素乙醇将是未来生物燃料乙 醇的主流路线 [4]。

2018 年，全球约有 2000 家燃料乙醇工厂处于 运行状态, 燃料乙醇年产量达到 $8.5 \times 10^{7} \mathrm{t}$, 同比增 长 $5.28 \%$ 。国际能源署 (IEA) 于 2018 年 10 月发 布了《2018 年可再生能源: 2018-2023 年市场分 
析和预测》, 认为可再生能源市场将继续扩张, 远 期可占全球能源消费增长量的 $40 \%$; 生物燃料产 量将增长 $15 \%$, 到 2023 年达到 $1.65 \times 10^{11} \mathrm{~L}$ （约 $\left.1.3 \times 10^{8} \mathrm{t}\right)$ 。根据美国可再生燃料协会 $(\mathrm{RFA})$ 公布 的数据, 美国作为燃料乙醇的主要生产国, 2018 年 燃料乙醇产量达到 $4.796 \times 10^{7} \mathrm{t}$, 占全球总产量的 $56 \%$; 巴西是乙醇全球第二大生产国，2018 年乙醇 产量达到 $2.365 \times 10^{7} \mathrm{t}$, 约占全球总产量的 $28 \%$; 欧 盟 1993 年生物燃料乙醇产量仅为 $4.8 \times 10^{4} \mathrm{t}$, 经过 十余年发展, 于 2004 年达到 $4.2 \times 10^{5} \mathrm{t}$, 随后开始 大幅增长并于 2006 年达到 $1.2 \times 10^{6} \mathrm{t}$ [5], 2018 年达 到 $4.27 \times 10^{6} \mathrm{t}$ ( 见表 1 )。无论是起步时间还是增长 速度, 欧盟生物燃料乙醇产业均不能和美国、巴西 等生物燃料乙醇大国相比, 但具备了较为牢固的生 物燃料乙醇产业基础。世界上多数国家均已发布推 广应用的相关法律或政策，燃料乙醇产业前景可期。

提升生产效率一直是燃料乙醇关键技术的研发 核心。这将使生产企业在多方面受益：一是提高现 有装置产能, 提升设备利用率和各操作单元的转化 效率; 二是优化产品结构, 通过分级利用实现产品 价值的最大化; 三是节约能源及水的消耗; 四是降 低 “三废” 排放; 五是降低新增产能的投资成本和 现有装置的生产成本，提升装置整体效益。未来的 装置工艺过程将会更加简洁、绿色, 设备更加稳定 可靠, 使产品在全生命周期内的碳排放及净能量、 污染物排放方面有更大的提升。合成生物学和分子 生物学作为先进生物技术的发展方向, 将在未来然 料乙醇产业发展中起到重要作用, 包括基因育种、 高效酶制剂、酵母等在内的多项生物技术正在全面 进入燃料乙醇产业链。国家非粮生物质能源工程技

表 12014 -2018 年世界燃料乙醇产量 $\quad \times 10^{4} \mathrm{t}$

\begin{tabular}{lccccc}
\hline 国家/地区 & 2014年 & 2015年 & 2016年 & 2017年 & 2018年 \\
\hline 美国 & 4274 & 4422 & 4578 & 4759 & 4796 \\
巴西 & 1849 & 2118 & 2179 & 2108 & 2365 \\
欧盟 & 432 & 414 & 411 & 423 & 427 \\
中国 & 190 & 243 & 252 & 261 & 314 \\
加拿大 & 152 & 130 & 130 & 134 & 143 \\
泰国 & 93 & 100 & 96 & 118 & 116 \\
阿根廷 & 48 & 63 & 79 & 93 & 99 \\
印度 & 46 & 63 & 67 & 84 & 87 \\
其他 & 258 & 117 & 146 & 139 & 164 \\
合计 & 7342 & 7670 & 7938 & 8119 & 8511 \\
\hline
\end{tabular}

数据来源：美国可再生燃料协会（RFA）。
术研究中心利用合成生物学技术构建得到乙醇耐受 性加强的工程菌 YM-27, 与原始酿酒酵母相比, 在 $12 \%$ 乙醇胁迫条件下, 生长量提升至 1.97 倍。 该菌株在木薯乙醇生产中运用, 可克服浓醪发酵 中后期酵母菌受高浓度乙醇抑制而导致发酵活力 不足的问题 [6]。将乙醇耐受性、渗透压耐受性提 高的酵母应用于浓醪发酵, 原料可快速糖化, 发 酵后无残糖剩余，乙醇终浓度接近 20\%（v/v) [7]。 采用发酵 - 渗透汽化耦合技术原位分离乙醇可以 减小产物抑制作用、提高单位体积产率 [8]。应用 生物技术使我国的燃料乙醇产业逐渐实现产品质 量的提高与生产成本的降低, 但由于我国现阶段 生产燃料乙醇的主要原料仍为玉米等粮食作物, 生产成本相对较高, 与美国和巴西存在较大差距。 此外, 相对煤制乙醇等其他燃料乙醇生产途径, 生物燃料乙醇的生产成本处于劣势。

近年来, 我国生物燃料乙醇生产线逐步实现了 自动化, 通过 “机器代人” 显著提升了生产效率, 同时降低了生产过程的人力劳动成本。然而, 生产 线的信息化和智能化程度依然偏低, 难以通过感知、 获取、分析生产线的全要素信息以进一步优化生产 线资源配置和生产力; 同时企业决策层难以及时了 解和掌握生产现场的实际情况, 导致管理难度大、 成本高。为保证生物燃料乙醇产业安全高效生产和 提升未来核心竞争力, 相关企业亟需通过新技术手 段进行资源整合、优化生产过程, 以提高自身产能、 降低生产成本，由此走出一条高质量发展路线。

此外，化工行业生产过程具有危险性大、连续 性强、规模大、生产工艺复杂等特点, 安全生产始 终是化工行业的第一基本准则。根据 2018 年全国 化工事故分析报告统计，2018 年全国范围内共发生 化工事故 176 起、死亡 223 人; 其中中毒和室息 事故 32 起、化学爆炸 26 起。化工企业目前仍缺 乏有效的生产过程智能管控平台, 企业存在监测 盲点多的安全隐患, 化工生产安全、环境安全仍 是众多化工企业的痛点问题。生物燃料乙醇产业 是集生物、化工、能源产业于一体的复合型产业, 安全生产同样是企业长远发展面临的重要挑战。

\section{三、生物燃料乙醇产业未来发展的新模式}

2019 年 7 月, 《流程型智能制造白皮书》正式 
发布, 在智能制造这一新的背景和机遇下, 流程型 制造业在设备运维和资产管理模式、生产模式、运 营模式、商业模式等方面都将发生显著变化 [9]。 为了保证企业安全高效生产、提升未来核心竞争力, 寻找生物燃料乙醇产业发展的新模式迫在眉睫。

利用智能控制、工业大数据、5G 网络等先进 信息化技术保证生物燃料乙醇企业的安全高效生 产, 这是寻找生物然料乙醇产业发展新模式的主要 方向。我国先后出台《关于深化制造业与互联网 融合发展的指导意见》《关于积极推进 “互联网 +” 行动的指导意见》《智能制造发展规划（20162020 年)》《关于深化 “互联网 + 先进制造业” 发展 工业互联网的指导意见》等政策文件, 为智能制造 发展提供了有力的政策支持, 标志着信息化与工业 化深度融合成为我国发展的新战略 $[10,11]$ 。5G 商 用进程快速推进, 将提供 10 倍于 $4 \mathrm{G}$ 网络的连接速 率, 网络延迟降低至 $1 \mathrm{~ms}$ 。5 $\mathrm{G}$ 网络的灵活便捷将 直接促进各行各业的数字化转型, 并为智能化发展 提供关键的网络基础设施。工业大数据是制造强国 建设技术路线图中的重要突破点, 以数据为核心构 建智能化体系有望成为支撑智能制造和工业互联网 的核心动力 [12]。

\section{（一）基于发酵过程大数据的智能生产新模式} 近年来, 与工业大数据相关的国家政策加快了
信息化与工业的深度融合，创新实现产业新模式。 2018 年, 中国信息通信研究院发布的《中国大数 据发展调查报告（2018 年)》显示，2016-2018 年 中国工业大数据市场规模稳步增长, 预计 20182020 年增速将保持在 $30 \%$ 以上。生物发酵过程具 有原料来源多样且不确定、发酵过程机理复杂、过 程变量维数众多且交互影响复杂、设备单元特征各 不相同等特点。同时, 生物发酵过程保存了海量的 历史生产数据, 这些数据蕴含着生产过程丰富的特 征信息 [13 15]。

生物燃料乙醇作为生物发酵的典型过程, 未来 生产过程的新模式可基于生产线的历史运行数据, 构建工艺知识图谱, 利用大数据分析和深度学习来 实现生产过程的建模与动态调度 (见图 1)：(1)针 对生物燃料乙醇生产过程原料来源不确定性造成的 全局单一模型难以精确描述生产过程的难点, 通过 基于层次聚类算法的生产条件宏观模态判别技术以 及对应的海量历史数据分割技术, 结合不同类别样 本构建对应类别的仿真模型, 为生物燃料乙醇生产 过程的智能化控制提供可靠样本数据; (2)针对目前 生物燃料乙醇生产线发酵和分离等关键工艺过程机 理认识不清的现状, 对模型关键参数、结构等进行 优化校正和自适应选择, 通过开展大数据的信息挖 掘来弥补机理认知的不足, 实现发酵和分离等生物 燃料乙醇生产线关键工艺过程的精确仿真; 同时通

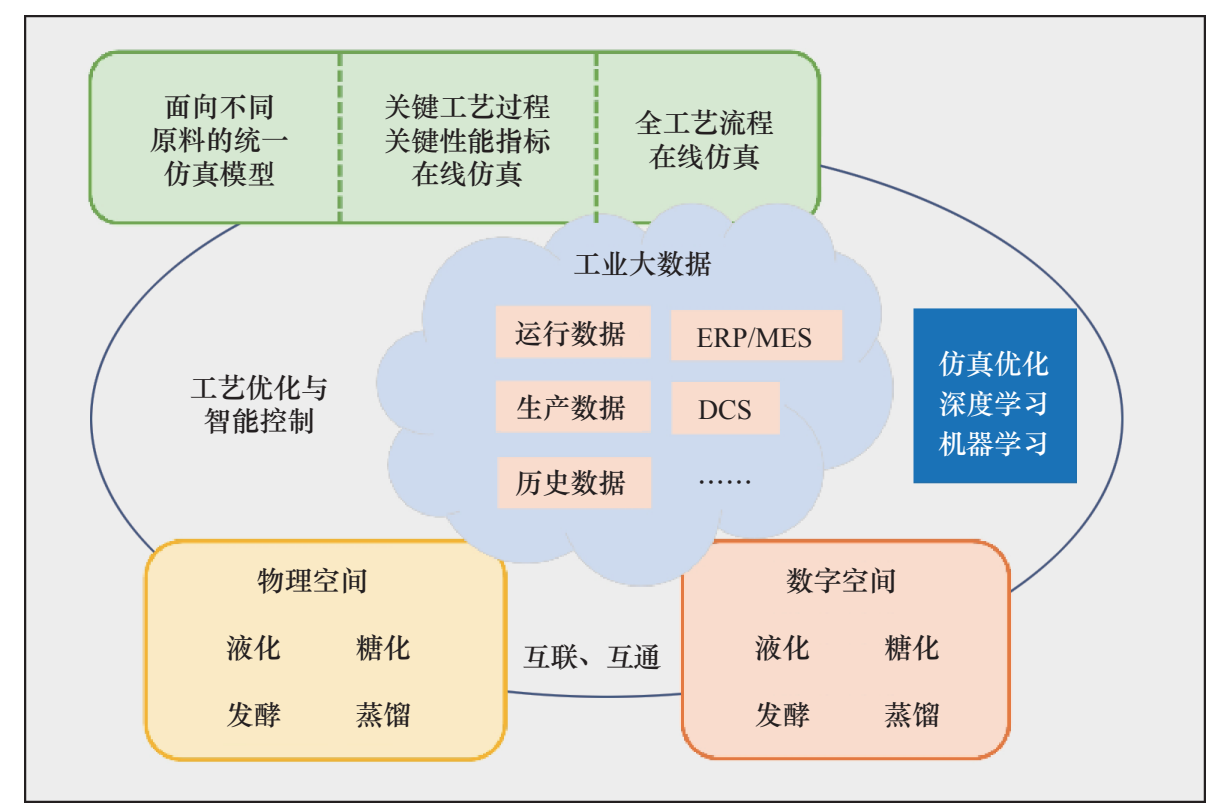

图 1 燃料乙醇产业生产过程新模式

注: ERP 为企业资源计划; MES 为制造执行系统; DCS 为集散控制系统。 
过大数据整合的关键工艺过程性能指标在线计算模 型, 进行关键性能指标精确计算, 用于指导生产过 程的全局优化, 实现生物燃料乙醇生产过程的智能 化控制。基于工业大数据, 结合先进控制、工艺优 化等技术, 使生产过程中的物料趋于平衡, 显著提 高生产效率、节约能源消耗, 构成了生物燃料乙醇 生产的新模式。

\section{（二）基于数字孪生技术的安全生产新模式}

生物燃料乙醇行业的生产设备需要长时间不 停机运行，传统的被动诊断与维护技术因其严重 的滞后效应和低自适应性而难以有效预示事故现 象。升级传统的诊断与维护技术, 使其具备主动 和自适应的状态评估能力, 这是保障设备安全运 行、提升作业质量、减少经济损失和避免人员伤 亡的有效方式。数字孪生、远程运维、故障诊断 等技术构成了燃料乙醇产业设备运维新模式的关 键技术（见图 2）[9]。

数字孪生的应用场景涵盖制造、建筑、医疗、 城市规划等，相关技术正在深刻地改变制造业: 美国国家航空航天局（NASA）在月球车、战斗 机、新型发动机等高端产业研发与制造方面成功 应用了数字孪生技术; 国内科大讯飞股份有限公 司发布了建设数字孪生城市计划; 在北京新机场
建设过程中, 通过对建筑物龙骨、管网等进行孪 生，提升建造效率的同时降低了 5\% 10\% 的建造 成本，缩短了 $10 \%$ 的建造工期。构建生物燃料乙 醇生产线数字孪生系统，建立涵盖多空间尺度和 多时间尺度的数字孪生对象模型, 可以实现设备 远程在线监测能力; 结合增强现实 (AR) 技术, 将设备数据实时传送至故障诊断专家, 直接指导 现场工作人员开展设备维修操作, 显著节约人工 成本。此外, 数字孪生系统提供三维沉浸式智能 巡检、工艺流程培训、操作培训、安环监控等功能, 成为解决大范围厂区、高危区域、恶劣天气下的 人工巡检、产线管理等难题的潜在手段。

预测性维护是建立在现代数字信号处理、人 工智能等先进技术基础上的一种新型设备维护方 式, 包括对燃料乙醇生产线装备进行实时监测和 故障报警，对设备运行数据实行远程分析和综合管 理, 赋予燃料乙醇生产线完善的自检和自诊断能 力 $[16,17]$ 。整合传感器检测、信号处理和大数据分 析技术，对生物燃料乙醇生产线的关键设备特征进 行动态观测和数据分析, 具备实时监测和诊断能力, 提早发现问题并及时部署维护方案，确保设备正常 运转, 将运行风险系数降到最低。通过燃料乙醇产 业设备运维的模式转变, 提高设备运维的效率和准 确性，保证相关企业的安全生产。

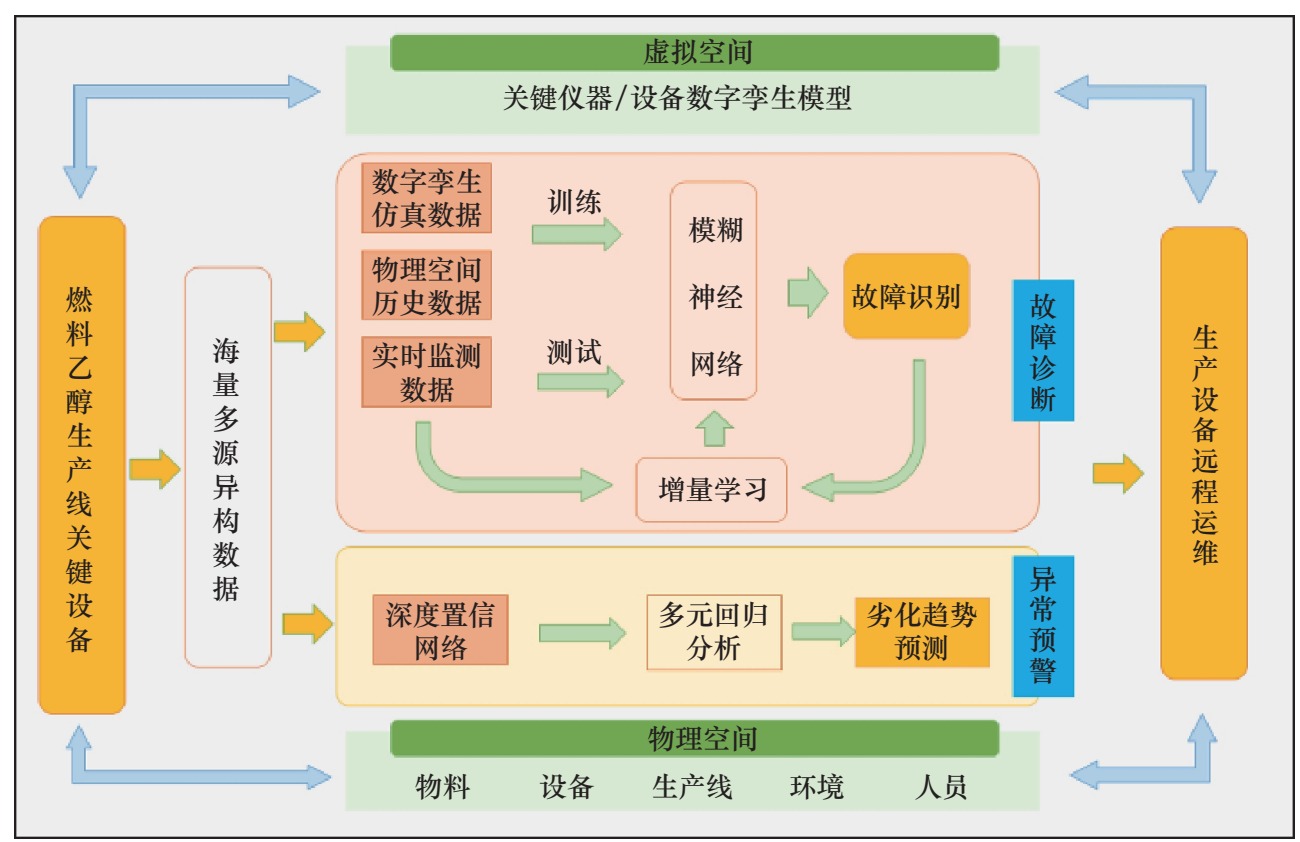

图 2 燃料乙醇产业设备运维新模式 


\section{（三）基于工业互联网和区块链技术的能源产业管 理新模式}

在国家政策的推动下，生物燃料乙醇产业发展 迅速, 但也面临着一些挑战, 比如如何使国家政策 更加高效地落地, 如何避免定价机制转换带来的影 响等。无论是在行业层面, 还是在企业层面, 对生 物燃料乙醇市场实施精益管理 (及全数字化管理) 都是非常必要的: 生产总量需要控制, 上下游各环 节需要协作, 避免市场失控, 既要消化多余的粮食 又要确保粮食储备处于安全线之上。因此, 采用工 业互联网和区块链技术打造燃料乙醇产业新管理模 式, 有助于生物燃料乙醇产业实施精益管理, 为国 家政策全方位执行、高质量推进提供保障。

2017 年以来, 我国工业互联网产业蓬勃发展, 传统制造企业、工业软件企业、工业设备供应商、 信息通信企业均开展了工业互联网平台的建设。构 建产业的互联网平台有助于打通上下游信息、整合 数据, 进而提升企业的管理效率 $[18,19]$ 。工业互联 网是第四次工业革命的关键支撑, $5 \mathrm{G}$ 是新一代信 息通信技术升级的重要方向, 二者的融合发展将推 动我国制造业转型升级, 支撑制造强国和网络强国 建设。目前 “ $5 \mathrm{G}+$ 工业互联网” 的研究与建设还处 于起步阶段, 在生物燃料乙醇产业的应用方面叒 待突破, 发展空间广阔。基于生物燃料乙醇企业 发展需求和行业政策, 以 “ $5 \mathrm{G}+$ 工业互联网” 为手 段, 对企业进行工业互联网内网设计、建设和管 理运维, 将分布于各地的生产企业连接起来, 通 过平台进行生产数据、工业模型、业务服务的积 累, 通过工业应用程序 (APP) 进行工业知识、经 验的传递和复制, 从而实现数据共享和产业链信 息集成。由此提升生产企业的管理水平，探索燃 料乙醇产业可持续发展的商业管理模式, 支持企 业转型、跨企业价值链延伸、全行业生态构建与 配置优化。

区块链技术作为新一代信息技术，是继蒸汽 机、电力、互联网之后的颠覆性创新, 将为新一轮 技术创新和产业变革带来新机遇 $[20,21]$ 。采用区块 链技术有助于解决能源行业 “三难” 问题: 一是 优化能源流程降低成本; 二是提高供应的安全性; 三是提供更多的可再生能源和低碳解决方案 [22]。 相关资料显示 [23], 目前能源行业采用区块链技 术的主要是电力企业和石油石化企业。区块链模
式在供应链金融平台和产品溯源平台等方面的应 用探索, 可作为生物燃料乙醇行业商业模式创新 的重要突破口。通过商业模式的转变, 推动企业 转型升级, 优化业务实施模式, 提高管理效率并 降低交易成本, 从而促进燃料乙醇产业的转型。

\section{四、对策建议}

\section{（一）关键技术攻关}

《国家可再生能源中长期发展规划》明确提出, 从长远考虑, 要积极发展以纤维素类生物质为原料 的生物燃料技术。目前 2 代纤维素乙醇发展的瓶颈 问题在于缺乏先进、高效、廉价的酶和工业菌种, 核心技术尚缺乏竞争力和抗风险能力, 尤其受制于 纤维原料综合利用水平差、技术集成度低等因素。 针对纤维素乙醇技术存在的技术瓶颈和市场需求, 函需有效整合不同学科和特定技术领域, 重点攻克 秸秆预处理、糖平台、生物转化、生化分离、生物 炼制和副产物联产等制约纤维醇类产业化发展的关 键技术, 将相关技术组合形成一套完整的技术体系。 在整体突破的基础上, 将解决方案整合集成为紧密 衔接的完整工艺包, 进行产业化示范和推广, 由此 保障我国油品质量升级和替代, 以期带来可观的经 济、社会和环境效益。

在近期, 建议将纤维素乙醇作为发展切入点, 推行互利共赢的理念, 与现有生产装置（1代或 1.5 代）进行深度整合，依托其公用工程来实现资 源的最大化利用, 从而降低纤维素乙醇工厂的整体 投资和运行成本。这是目前行业先行者认可和推崇 的新模式, 预期具有可观的综合效益。

\section{（二）政策保障}

加强顶层设计, 从国家战略层面引导产业发展, 加快制定培育生物燃料产业智能化发展的专项纲领 性文件。加强组织管理, 尽快建立国家生物液体燃 料推广和研发工作协调机制, 成立国家生物液体燃 料工作领导小组, 统筹生物燃料乙醇生产和车用乙 醇汽油推广使用工作。健全生物燃料乙醇产业标准 体系。

地方政府在国家战略明确的基础上，开展体制 机制改革试点, 积极促进产业新形态形成。针对现 有产业规模企业、基地和集群，出台相关政策，对 
产业智能化升级和建设给予必要扶持，加强对相关 企业政策优惠支持。鼓励人才、技术、资金向优势 区域集中，引导生物燃料乙醇产业基地特色化、联 合化、智能化发展，有步骤、有重点地培育若干世 界级生物液体燃料产业集群，在有条件的地区开展 生物液体燃料新技术和新模式示范。

企业层面注重创新生产模式和生产技术，加强 与科研机构合作，坚持自主研发与引进吸收并举、 基础研究与商业化应用结合的原则，建立完善以企 业为主体、市场为导向、产学研相结合的技术创新 体系。加强创新平台建设, 增强自主研究能力, 集 中力量突破关键共性技术，探索适合国情的先进生 物燃料技术路线。积极配合国家政策导向，提升市 场竞争力，提高企业内部工作效率，支撑生物燃料 乙醇产业的高质量发展。

\section{参考文献}

[1] 中华人民共和国全国人民代表大会. 中华人民共和国可再生能 源法 [M]. 北京: 法律出版社, 2005.

The National People's Congress of the PRC. Law of the People's Republic of China on renewable energy [M]. Beijing: Law Press. China, 2005.

[2] 中国工程科技发展战略研究院. 2019中国战略性新兴产业发展 报告 [M]. 北京: 科学出版社, 2019 .

China Academy of Engineering Science and technology Development Strategy. China's strategic emerging industry development report 2019 [M]. Beijing: China Science Publishing \& Media Ltd., 2019.

[3] 国家发展和改革委员会创新和高技术发展司, 中国生物工程学 会. 中国生物产业发展报告2018 [M]. 北京: 化学工业出版社, 2018.

Innovation and High Technology Development Division of National Development and Reform Commission, Chinese Society of Bioengineering. Annual report on bioindustry in China: 2018 [M]. Beijing: Chemical Industry Press, 2018.

[4] 毛开云, 范月蕾, 王跃, 等. 国内外燃料乙醇产业现状+深度解析 [J]. 高科技与产业化, 2018, 265(6): 8-15.

Mao K Y, Fan Y L, Wang Y, et al. Status quo of fuel ethanol industry at home and abroad + in-depth analysis [J]. HighTechology and Industrialization, 2018, 265(6): 8-15.

[5] 靳胜英. 世界燃料乙醇产业发展态势 [J]. 石油科技论坛, 2011 (2): 52-54.

Jin S Y. Development trend of fuel ethanol industry in the world [J]. Petroleum Science and Technology Forum, 2011 (2): 52-54.

[6] 秦艳, 申乃坤, 王青艳, 等. 乙醇耐受性提高的酿酒酵母基因工 程菌株的构建 [J]. 可再生能源, 2016 (34): 1096-1100.

Qin Y, Shen N K, Wang Q Y, et al. Construction of genetically engineered Saccharomyces cerevisiae strains with improved ethanol tolerance $[\mathrm{J}]$. Renewable Energy Resources, 2016 (34): 1096-1100
[7] 丁文涛. 提高酿酒酵母浓醪发酵乙醇产量的研究 [D]. 天津: 天 津大学 (博士学位论文), 2013.

Ding W T. Study on the improvement of ethanol production by high gravity fermentation of Saccharomyces cerevisiae [D]. Tianjin: Tianjin University (Doctoral dissertation), 2013.

[8] 孙亚东, 蒋建新, 孙由, 等. 纤维乙醇及渗透汽化原位分离技术 研究进展 [J]. 中国能源, 2008 (9): 23-27.

Sun Y D, Jiang J X, Sun R, et al. Research progress of fiber ethanol and pervaporation in situ separation technology [J]. China Energy, 2008 (9): 23-27.

[9] 中国电子技术标准化研究院, 深圳华制智能制造技术有限公司, 东北大学. 流程型智能制造白皮书 [R]. 北京: 中国电子技术标 准化研究院, 2019.

China Institute of Electronic Technology Standardization, Shenzhen Huazhi Intelligent Manufacturing Technology Co., Ltd., Northeast University. White paper on process intelligent manufacturing [R]. Beijing: China Institute of Electronic Technology Standardization, 2019.

[10］德勤企业风险管理服务部. 工业4.0时代的长效驱动力一一两化 融合 $[\mathrm{M}]$. 上海: 上海交通大学出版社, 2015 .

Deloitte Enterprise Risk Management Service Department. Long term driving force in the era of industry 4.0: Integration of two industries [M]. Shanghai: Shanghai Jiaotong University Press, 2015.

[11] Zhou J, Li P G, Zhou Y H, et al. Toward new-generation intelligent manufacturing [J]. Engineering, 2018, 4(1): 11-20.

[12] 王基铭. 我国石化产业面临的挑战及对策建议 [J]. 当代石油石 化, 2015, 23(11): 1-7.

Wang J M. Challenges facing China's petrochemical industry and their countermeasure suggestions [J]. Petroleum \& Petrochemical Today, 2015, 23(11): 1-7.

[13] Zhang S L, Chu J, Zhuang Y P. A multi-scale study on industrial fermentation processes and their optimization [J]. Advances in Biochemical Engineering and Biotechnology, 2004, 87: 97-150.

[14] 庄英萍, 田锡炜, 张嗣良. 基于多尺度参数相关分析的细胞培养 过程优化与放大 [J]. 生物产业技术, 2018 (1): 49-55.

Zhuang Y P, Tian X W, Zhang S L. Optimization and amplification of cell culture process based on multi-scale parameter correlation analysis [J]. Biotechnology \& Business, 2018 (1): 49-55.

[15] 张嗣良, 储炬. 多尺度微生物过程优化 [M]. 北京: 化学工业出 版社, 2003

Zhang S L, Chu J. Multi scale microbial process optimization [M]. Beijing: Chemical Industry Press, 2003.

[16] 余骋远. 基于工业大数据的设备健康与故障分析方法研究与应 用 [D]. 沈阳: 中国科学院沈阳计算技术研究所 (硕士学位论文), 2017.

Yu P Y. Research and application of equipment health and fault analysis method based on industrial big data [D]. Shenyang: Shenyang Institute of computing technology, Chinese Academy of Sciences (Master's thesis), 2017.

[17] 徐暗杰. 工业大数据挖掘分析及应用前景研究 [J]. 电子技术与 软件工程, 2016 (22): 159-159.

$\mathrm{Xu}$ Y J. Industrial big data mining analysis and application prospect research $[\mathrm{J}]$. Electronic Technology and Software Engineering, 2016 (22): 159-159. 
[18] 陈肇雄. 工业互联网是智能制造的核心 [J]. 中国信息化, 2016 (1): 7-8

Chen Z X. Industrial Internet is the core of intelligent manufacturing [J]. China Informatization, 2016 (1): 7-8.

[19］王晨. 拥抱工业互联网的正确姿势: 业务驱动, “造一把可 靠的锤子” [N/OL]. 中国科学报, 2018-10-11 (5). http://news. sciencenet.cn/sbhtmlnews/2018/10/339768.shtm?id=339768.

Wang C. Embrace the right posture of industrial internet: Business driven, "build a reliable hammer" [N/OL]. China Science Daily, 2018-10-11 (5). http://news.sciencenet.cn/ sbhtmlnews/2018/10/339768.shtm?id=339768.

[20] 金盛翔. 区块链, 如何定义未来生活? [J]. 杭州(周刊), 2018, 502(18): 8-11.

Jin S X. Blockchain, how to define future life? [J]. Hangzhou
Weekly, 2018, 502 (18): 8-11.

[21] 元一航. 基于SDN智能体的工业网络流量调度机制研究 [D]. 浙 江: 浙江工商大学 (硕士学位论文), 2019.

Qi Y H. Research on traffic scheduling mechanism in industrial network based on SDN intelligence [D]. Zhejiang, Zhejiang Gongshang University (Master's thesis), 2019.

[22] 尚舵. 区块链技术在能源行业的应用前景 [J]. 电力信息与通信 技术, 2019, 17(2): 5-12.

Shang D. Application prospect of blockchain technology in energy industry [J]. Electric Power Information and Communication Technology, 2019, 17 (2): 5-12.

[23] Metelitsa C. Blockchain for energy 2018: Companies and applications for distributed ledger technologies on the grid [R]. San Francisco: Greentech Media Inc., 2018. 